\title{
Evaluation of the Relationship between Alexithymia and Dental Fear in Individuals Undergoing Tooth Extraction for Orthodontic Reasons
}

\author{
Levent Cigerim ${ }^{1}$, Saadet Cinarsoy Cigerim²
}

\begin{abstract}
Aim and objective: In this study, it was aimed to evaluate the alexithymia and dental fear levels and to reveal the relationship between alexithymia and dental fear of healthy individuals undergoing tooth extraction for orthodontic reasons.

Materials and methods: This prospective, cross-sectional study was conducted between June 2019 and December 2019 in orthodontic patients who had their teeth extracted in Van Yuzuncu Yil University, Faculty of Dentistry, Oral, Maxillofacial Surgery and Orthodontics Department and a private dental clinic in Van province. Questionnaires consisted of the Toronto Alexithymia Scale-20, which determines the level of alexithymia and the Dental Fear Scale, which measures dental fear levels were performed 1 week after the tooth extractions.

Results: Of the 260 individuals included in the study, 180 were female and 80 were male. The age of individuals ranged from 11 to 41 , and the mean age was $19.97 \pm 5.82$. There was no statistically significant difference between the rates of alexithymia in individuals by age and gender ( $p$ value $>0.05$ ). The levels of dental fear and alexithymia of individuals do not differ statistically according to the place of treatment ( $p$ value $>0.05$ ). The positive relationship between individuals' dental fear and alexithymia levels was found to be statistically significant $(r=0.239, p$ value $<0.01)$.

Conclusion: In this study, it was revealed that when individuals' level of dental fear increased, the level of alexithymia increased.

Clinical significance: The presence of alexithymia should be investigated in individuals who are considered to have difficulty in cooperating because of dental fear in the clinic. Both dental fears and alexithymies of individuals should be handled separately before dental treatment.
\end{abstract}

Keywords: Alexithymia, Dental fear, Tooth extraction.

Journal of Contemporary Dentistry (2019): 10.5005/jp-journals-10031-1267

\section{INTRODUCTION}

The concept of alexithymia is the difficulty of expressing emotions in general. Alexithymic individuals have somatic complaints, feelings, and problems expressing themselves verbally. ${ }^{1}$ Alexithymics exhibit elaborate and repetitive behaviors while speaking, while acting superficially during their communication with other people. ${ }^{2}$ There are differing opinions that alexithymia is related to a neurological disease, a psychosomatic condition, a cognitive problem, an emotional inadequacies, or personality traits. It is thought that it is more accurate to talk about the level of alexithymia properties rather than the presence of alexithymia in individuals. ${ }^{3}$ It is effective in the formation of alexithymia in sociocultural factors as well as personality characteristics, such as age, gender, and education level. ${ }^{4-6}$ In today's people who spend a lot of time in virtual environments, it is seen that the alexithymic properties increase. ${ }^{7}$ Methods such as cognitive approach, behavioral approach, selfrelieving training, attachment training, and biofeedback are recommended for the treatment of alexithymic properties. ${ }^{8-10}$

Dental fear is one kind of fear that people experience. Fear or dislike of going to the dentist contains the fears created by the individual in his own world. Although active local anesthetics and analgesics are routinely used today, some patients are afraid to go to the dentist. Dental fear can cause psychological problems in individuals, as well as deterioration of the oral health of individuals and, consequently, their general health. ${ }^{11}$

During dental treatments, patients have varying levels of fear and anxiety. ${ }^{12}$ Patients who can express their feelings comfortably can communicate easily with the physician. Patients who cannot
${ }^{1}$ Department of Oral and Maxillofacial Surgery, Van Yuzuncu Yil University, Faculty of Dentistry, Van, Turkey

${ }^{2}$ Department of Orthodontics, Van Yuzuncu Yil University, Faculty of Dentistry, Van, Turkey

Corresponding Author: Levent Cigerim, Department of Oral and Maxillofacial Surgery, Van Yuzuncu Yil University, Faculty of Dentistry, Van, Turkey, Phone: +90 532163 3287, e-mail: levent139@hotmail.com How to cite this article: Cigerim L, Cigerim SC. Evaluation of the Relationship between Alexithymia and Dental Fear in Individuals Undergoing Tooth Extraction for Orthodontic Reasons. J Contemp Dent 2019;9(3):109-112.

Source of support: Nil

Conflict of interest: None

express their feelings for various reasons cannot exactly state what they expect from the treatment and their discomfort. The failure of the physician to get a clear answer to the questions asked can also negatively affect the course of treatment and cause patientphysician mismatch. In terms of the success of the diagnosis and treatment process in dentistry, the cooperation of patients is very important. ${ }^{7}$ In individuals with alexithymic and/or dental fear, such problems are more likely to occur. For this reason, we think that it is important to reveal the relationship between alexithymia and dental fear in the management of these patients. In this study, it was aimed to evaluate the alexithymia and dental fear levels and to reveal the relationship between alexithymia and dental fear of healthy individuals undergoing tooth extraction for orthodontic reasons. 


\section{Materials and Methods}

This prospective, cross-sectional study was conducted between June 2019 and December 2019 in orthodontic patients who had their teeth extracted in Van Yuzuncu Yil University Faculty of Dentistry, Oral and Maxillofacial Surgery, and Orthodontics Department and a private dental clinic in Van province. The study included healthy individuals without any systemic disease, individuals with sufficient cognitive levels to fill out the survey. Individuals with dental pain were excluded from the study when filling out the surveys. For the study, approval was obtained from the Ethics Board of Van Yuzuncu Yil University Faculty of Medicine in accordance with the Helsinki Declaration. Patients have been informed in detail about the study. Patients who volunteered by signing the "Informed Consent Form" (taking the consents of their parents for those under 18 years of age) were asked to fill out the surveys given to them. Questionnaires consisted of the Toronto Alexithymia Scale (TAS)-20,13 which determines the level of alexithymia, and the Dental Fear Scale (DFS), ${ }^{14}$ which measures dental fear levels were performed one week after the tooth extractions. Those who scored 61 or more from TAS-20 were considered alexithymic. Scores less than 40 in DFS were considered as "low dental fear," scores between 40 and 60 were considered "medium dental fear," scores between " 60 and 80 " were high dental fear, and scores of 80 and above were considered as severe dental fear.

\section{Statistical Analysis}

Number Cruncher Statistical System 2007 (Kaysville, Utah, USA) software was used for the statistical analyses. The data were analyzed with descriptive statistics (mean, standard deviation, median, frequency, percentages, minimum, and maximum). The Mann-Whitney $U$ test was used for the comparison of non-normally distributed variables. Pearson Chi-square test and Fisher Freeman Halton test were used to compare the qualitative data. Spearman correlation analysis was used to evaluate the relationships between quantitative variables. The $p$ value $<0.05$ was accepted as significant.

\section{Results}

Of the 260 individuals included in the study, 69.2\% $(n=180)$ were female and $30.8 \%(n=80)$ were male. The age of individuals ranged from 11 to 41 , and the mean age was $19.97 \pm 5.82$. The frequency, financial status, and professions of individuals and brushing their teeth are shown in Table 1.

There was no statistically significant difference between the rates of alexithymia in individuals by age and gender ( $p$ value $>$ 0.05), (Table 2).

Statistically significant differences were found between the distribution of dental fear levels of individuals by age ( $p$ value $<$ 0.01). The high incidence of dental fear in individuals aged 18 and below was significantly lower than in individuals older than 18 years of age ( $p$ value $<0.01$ ) (Table 2 ).

Statistically significant differences were found between the distribution of dental fear levels of individuals by gender ( $p$ value $<$ $0.01)$. Low incidence of dental fear in male was significantly higher ( $p$ value $<0.01$ ), while moderate incidence of dental fear in female was significantly higher ( $p$ value $<0.05$ ) (Table 2 ).

The levels of dental fear and alexithymia of individuals do not differ statistically according to the place of treatment ( $p$ value $>$ 0.05) (Table 3).

\begin{tabular}{llc}
\multicolumn{3}{l}{ Table 1: Description of demographic characteristics } \\
\hline Age & Min-Max & $11-41$ \\
& Mean \pm SD & $19.97 \pm 5.82$ \\
& $\leq 18$ & $128(49.2 \%)$ \\
Frequency of daily & $>18$ & $132(50.8 \%)$ \\
tooth brushing & 2 & $16(6.2 \%)$ \\
& 3 & $121(46.5 \%)$ \\
& 4 & $94(36.2 \%)$ \\
Occupation & 5 & $21(8.1 \%)$ \\
& Non-working & $8(3.1 \%)$ \\
& Health worker & $14(5.4 \%)$ \\
& Self-employment & $16(6.2 \%)$ \\
& Student & $16(6.2 \%)$ \\
& Teacher & $45(17.3 \%)$ \\
& Housewife & $4(1.5 \%)$ \\
Financial situation & Middle & $149(57.3 \%)$ \\
& Good & $106(40.8 \%)$ \\
& Very good & $5(1.9 \%)$
\end{tabular}

$\mathrm{SD}$, standard deviation

The positive relationship between individuals' dental fear and alexithymia levels was found to be statistically significant $(r=0.239$, $p$ value $<0.01$ ). As individuals' level of dental fear increased, the level of alexithymia increased (Table 4).

\section{Discussion}

In this study, the alexithymia and dental fear levels of individuals admitted to the private dental clinic and the faculty of dentistry were evaluated. The higher dental fear rate in individuals aged 18 and younger was lower, while the incidence of low dental fear in male was found to be higher in female with a higher incidence of moderate dental fear. In individuals, the higher the level of perception, the higher the level of dental fear.

Smith, ${ }^{15}$ Feiguine et al., ${ }^{16}$ Viinikangas et al., ${ }^{17}$ Pohjola et al., ${ }^{18}$ and Sezer et al. ${ }^{19}$ found that male individuals have higher levels of alexithymia. In this study, unlike the studies mentioned, there was no difference in the level of alexithymia by gender. Paulson, ${ }^{20}$ Krystal et al., ${ }^{21}$ and Martin and $\mathrm{Pihl}^{22}$ reported that alexithymia was not associated with age. In this study, similarly, there was no difference in age at the level of alexithymia.

There are very few studies in the literature that evaluate the relationship of alexithymia with dental fear. From these studies, Viinikangas et al. ${ }^{17}$ evaluated dental anxiety and alexithymia on 669 individuals and noted that the incidence of alexithymia is higher in individuals with high dental anxiety. In the Pohjola et al. ${ }^{18}$ study, 5,241 individuals examined the relationship between dental fear and alexithymia. They reported that alexithymic individuals have higher dental fear. Sipila et al. ${ }^{23}$ showed that temporomandibular dysfunction symptoms and orofacial pain were associated with alexithymia. Sezer et al. ${ }^{19}$ reported that alexithymia is more common in individuals with chronic periodontitis, and alexithymia is a possible risk factor for chronic periodontitis. Stein et al. ${ }^{24}$ showed that inadequate oral healthcare was associated with alexithymia and stated that alexithymia may be a possible factor in poor oral and dental health. Jerlang 
Table 2: Evaluation of frequency of alexithymia and dental fear according to age and gender

\begin{tabular}{|c|c|c|c|c|c|c|}
\hline & & \multicolumn{2}{|c|}{ Dental fear } & \multicolumn{3}{|c|}{ Alexithymia } \\
\hline & & Low & Middle & High & Normal & Alexithymic \\
\hline \multirow[t]{3}{*}{ Age; $n(\%)$} & $\leq 18$ & $94(73.4)$ & $34(26.6)$ & $0(0.0)$ & $118(92.2)$ & $10(7.8)$ \\
\hline & $>18$ & $80(60.6)$ & $43(32.6)$ & $9(6.8)$ & $124(93.9)$ & $8(6.1)$ \\
\hline & & $p$ & ${ }^{\mathrm{a}} 0.002^{*}$ & & ${ }^{b} 0.578$ & \\
\hline \multirow[t]{3}{*}{ Gender; $n$ (\%) } & Female & $109(60.6)$ & $62(34.4)$ & $9(5.0)$ & $171(95.0)$ & $9(5.0)$ \\
\hline & Male & $65(81.3)$ & $15(18.8)$ & $0(0.0)$ & 71 (88.8) & $9(11.3)$ \\
\hline & & $p$ & ${ }^{\mathrm{b}} 0.002^{*}$ & & ${ }^{\mathrm{b}} 0.067$ & \\
\hline
\end{tabular}

${ }^{\mathrm{a}}$ Fisher Freeman Halton Test, ${ }^{\mathrm{b}}$ Pearson Chi-square test, ${ }^{*} p$ value $<0.01$

Table 3: Evaluation of the alexithymia and dental fear according to place of treatment

\begin{tabular}{lllll}
\hline & & \multicolumn{2}{c}{ Place of treatment } \\
\cline { 3 - 4 } Dental Fear & Min-Max & $10-79$ & Faculty of Dentistry & $16-66$ \\
& Mean \pm SD & $35.24 \pm 12.28$ & $34.89 \pm 10.91$ & $35.60 \pm 13.55$ \\
& Low & $174(66.9 \%)$ & $90(69.2 \%)$ & $84(64.6 \%)$ \\
& Middle & $77(29.6 \%)$ & $38(29.2 \%)$ & $39(30.0 \%)$ \\
Alexithymia & High & $9(3.5 \%)$ & $2(1.5 \%)$ & $7(5.4 \%)$ \\
& Min-Max & $25-75$ & $28-75$ & $25-75$ \\
& Mean \pm SD & $46.01 \pm 9.64$ & $46.54 \pm 9.11$ & $45.48 \pm 10.15$ \\
& Normal & $242(93.1 \%)$ & $122(93.8 \%)$ & $120(92.3 \%)$ \\
\end{tabular}

'Student- $t$ test, SD: standard deviation

Table 4: Evaluation of the relationship between dental fear and alexithymia

\begin{tabular}{lll}
\hline & \multicolumn{2}{c}{ Dental fear score } \\
\cline { 2 - 3 } & \multicolumn{1}{c}{$p$} \\
\hline Alexithymia score & 0.239 & $0.001^{*}$ \\
\hline$r=$ Pearson correlation coefficient, ${ }^{*} p$ value $<0.01$
\end{tabular}

et al. ${ }^{25}$ found that in 20 females with burning mouth syndrome, the majority of individuals were alexithymic and stated the importance of a different assessment and treatment approach for these patients. As can be seen in the aforementioned studies, it has been shown that alexithymia in individuals may be associated with insufficient oral health and many disorders in the orofacial region. In addition, as the level of alexithymia increases in these individuals, dental fear and dental anxiety level increase. Similarly, in this study, it was observed that individuals with high dental fear level had higher alexithymia levels.

\section{Conclusion}

Within the limitations of this study, there was a positive relationship between alexithymia and dental fear. There was no effect of the place of treatment (dentistry faculty, private dental clinic) on alexithymia and dental fear levels of patients. The desired patient-physician relationship may not be achieved in alexithymic individuals who apply to the dentist. Further studies are needed in patients with alexithymia, where dental fear and/or dental anxiety is assessed in larger patient populations.

\section{Clinical Significance}

The presence of alexithymia should be investigated in individuals who are considered to have difficulty in cooperating because of dental fear in the clinic. Both dental fears and alexithymies of individuals should be handled separately before dental treatment.

\section{References}

1. Sifneos PE. The prevalence of 'alexithymic' characteristics in psychosomatic patients. Psychother Psychosom 1973;22(2):255-262. DOI: 10.1159/000286529.

2. Lesser IM. A review of the alexithymia concept. Psychosom Med 1981;43(6):531-543. DOI: 10.1097/00006842-198112000-00009.

3. Beach M. Alexithymia and somatization: relationship to DSM III-R diagnoses. J Psychosom Res 1994;38(6):529-535. DOI: 10.1016/00223999(94)90050-7.

4. Mattila AK, Poutanen O, KoIvisto AM, et al. Alexithymia and life satisfaction in primary healthcare patients. Psychosomatics 2007;48(6):523-529. DOI: 10.1176/appi.psy.48.6.523.

5. Vadacca M, Bruni R, Cacciapaglia F, et al. Alexithymia and immünoendocrine parameters in patients affected by systemic lupus erythematosusu and rheumatoid arthritis. Rheumatismo 2008;60(1):50-56.

6. Mattila AK, Saarni SI, Salminen JK, et al. Alexithymia and healthrelated quality of life in a general population. Psychosomatics 2009;50(1):59-68. DOI: 10.1176/appi.psy.50.1.59.

7. Koçak R. Aleksitimi: kuramsal çerçeve tedavi yaklaşımları ve ilgili araştırmalar, Ankara University Faculty of Educational Sciences. J Spec Educ 2002;35(1):2.

8. Larsen JK, Brand N, Bermond B, et al. Cognitive and emotional characteristics of alexithymia: a review of neurobiological 
studies. J Psychosom Res 2003;54(6):533-541. DOI: 10.1016/S00223999(02)00466-X.

9. Maria Luisa O, Marianna T, Mariangela S, et al. Alexithymia and aging a neuropsychological perspective. J Nerv Ment Dis 2010;198(12): 891-895. DOI: 10.1097/NMD.0b013e3181fe743e.

10. Rickles WH, Onoda L, Doyle CC. Task force study section report: biofeedback as an adjunct to psychotherapy. Biofeedback Self Regul 1982;7(1):1-33. DOI: 10.1007/BF00999052.

11. Berggren U, Carlson GS, Hakeberg M, et al. Assesment of patients with phobic dental anxiety. Acta Odontol Scand 1997;55(4):217-222. DOI: 10.3109/00016359709115420.

12. Boorin MR. Anxiety its manifestation and role in the dental patient. Dent Clin North Am 1995;39(3):523-537.

13. Bagby RM, Parker JD, Taylor GJ. The twenty-item Toronto Alexithymia Scale-I.Item selection and cross-validation of the factor structure. J Psychosom Res 1994;38(1):23-32. DOI: 10.1016/0022-3999(94) 90005-1.

14. Kleinknecht RA, Klepac RK, Alexander LD. Origins and characteristics of fear of dentistry. J Am Dent Assoc 1973;86(4):842-848. DOI: 10.14219/jada.archive.1973.0165.

15. Smith GJ. Alexithymia in medical patients referred to a consultation / liason service. Am J Psychiatry 1983;140(1):99-101. DOI: 10.1176/ ajp.140.1.99.

16. Feiguine RJ, Jones NF, Kassel PA. Distribution of alexithymic characteristics within an adult outpatient population. Psychother Psychosom 1988;50(2):61-67. DOI: 10.1159/ 000288101.
17. Viinikangas $A$, Lahti $S$, Tolvanen $M$, et al. Dental anxiety and alexithymia: gender differences. Acta Odontol Scand 2009;67(1): 13-18. DOI: 10.1080/00016350802459264.

18. Pohjola V, Mattila AK, Joukamaa M, et al. Dental fear and alexithymia among adults in Finland. Acta Odontol Scand 2011;69(4):243-247. DOI: 10.3109/00016357.2011.554861.

19. Sezer U, Üstün $\mathrm{K}$, Şenyurt $\mathrm{SZ}$, et al. Relationship between alexithymia and chronic periodontitis. Niger J Clin Pract 2017;20(5):530-536. DOI: 10.4103/1119-3077.183244.

20. Paulson JE. Stale of the art of alexithymia measurement. Psychother Psychosom 1985;44(2):57-64. DOI: 10.1159/000287894.

21. Krystal JH, Güler EL, Cichetti DV. Assessment of alexithymia in posttraumatic stress disorder and somatic illness-introduction of a reliable measure. Psychosom Med 1986;48(1-2):84-94. DOI: 10.1097/00006842-198601000-00007.

22. Martin BJ, Pihl OR. Influence of alexithymia characteristics on psychological and subjective stress responses in normal individuals. Psychother Psychosom 1986;45(2):66-77. DOI: 10.1159/000287930.

23. Sipila K, Veijola J, Jokelainen J, et al. Association between symptoms of temporomandibular disorders and depression: an epidemiological study of the Northern Finland 1966 birth cohort. Cranio 2001;19(3):183-187. DOI: 10.1080/08869634.2001.11746168.

24. Stein L, Bergdahl M, Pettersen KS, et al. Exploring the association between oral health literacy and alexithymia. Community Dental Health 2015;32(3):143-147.

25. Jerlang BB. Burning mouth syndrome (BMS) and the concept of alexithymia - a preliminary study. J Oral Pathol Med 1997;26(6): 249-253. DOI: 10.1111/j.1600-0714.1997.tb01232.x. 